\title{
Phase Change Material for Temperature Control of Loop Heat Pipe Compensation Chamber
}

\author{
Michael K. Choi ${ }^{*}$ \\ NASA Goddard Space Flight Center, Greenbelt, MD 20771
}

\begin{abstract}
The compensation chamber (CC) of a loop heat pipe (LHP) requires a stable temperature. In the current technology, the CC is commonly cold biased by exposing it to deep space, and active heater control is used to maintain its temperature stable. Heater power required for a typical LHP with a $300 \mathrm{~W}$ heat transport capacity is as much as $25 \mathrm{~W}$. If multiple LHPs are used, heater power requirement could be a bigger issue. Also heater controller or temperature sensor failure could lead to a LHP or mission failure. This paper presents an innovative concept of using phase change material (PCM) for temperature control of LHP CC. Some of the electronics and/or detector assembly waste heat is stored in the PCM and transferred to the LHP CC by constant conductance heat pipes (CCHPs). Phase change of the PCM occurs at a constant temperature and maintains the LHP CC temperature stable. It eliminates heater power and active heater control for the $\mathrm{CC}$. It also increases the reliability of LHP.
\end{abstract}

\section{Nomenclature}

$\begin{array}{ll}\text { BAT } & =\text { Burst Alert Telescope } \\ C & =\text { carbon } \\ C C & =\text { compensation chamber } \\ C C H P & =\text { constant conductance heat pipe } \\ \text { GLAS } & =\text { Geoscience Laser Altimeter System } \\ \text { GOES } & =\text { Geostationary Operational Environmental Satellite } \\ H & =\text { hydrogen } \\ J E M & =\text { Japanese Experiment Module } \\ \text { LHP } & =\text { loop heat pipe } \\ M A X I & =\text { Monitor of All-sky X-ray Image } \\ N & =\text { carbon number } \\ P C M & =\text { phase change material } \\ T E S & =\text { Tropospheric Emission Spectrometer } \\ V C H P & =\text { variable conductance heat pipe }\end{array}$

\section{Introduction}

$\boldsymbol{U}$ SAGE of loop heat pipe (LHP) for heat rejection systems that cool instruments of NASA missions, commercial telecom satellites and Department of Defense satellites continues to increase. The advantages of LHP are high heat transport capability, flexibility of evaporator and condenser locations, and ground testability (no gravity issue). ${ }^{1,2}$ Typically the LHP evaporator is thermally coupled to the electronics and/or detector assembly to remove the waste heat. Examples of NASA missions that use LHP for instrument cooling are Swift BAT, IceSat GLAS, GOES, JEM-MAXI and TES. An example of satellites that uses LHP as thermal link between internal high power electronics and remote radiators is INMARSAT-4. The compensation chamber (CC) of LHP requires a stable temperature. In the current technology, the CC is commonly cold biased by exposing it to deep space, and active heater control is used to maintain its temperature stable. ${ }^{3,4}$ Heater power required for a typical LHP with an approximately $300 \mathrm{~W}$ heat transport capacity is as much as $25 \mathrm{~W}$. It increases the electrical power budget and

\footnotetext{
* Senior Aerospace Engineer, Heat Transfer, AIAA Associate Fellow.
} 
spacecraft solar array size. If multiple LHPs are used, for example two on Swift BAT, heater power requirement could be a bigger issue. Also heater controller or temperature sensor failure could lead to a LHP or mission failure.

\section{Objective}

The objective of this paper is to present an innovative concept of using phase change material (PCM), instead of active heater control, for temperature control of LHP CC.

\section{PCM for Temperature Control of LHP CC}

Figure 1 illustrates the innovative concept of using PCM for temperature control of LHP CC in this paper. Figure 2 presents a functional block diagram for this concept. The evaporator of a variable conductance heat pipe (VCHP) is thermally coupled to the LHP evaporator. A PCM heat exchanger is swaged over the VCHP condenser to allow heat exchange between the VCHP condenser and PCM. The PCM is filled in a $1 \mathrm{~cm}$ thick aluminum honeycomb panel which has constant conductance heat pipe (CCHP) spreaders attached to its aluminum face sheet. K1100 carbon fibers, which have high thermal conductivity, are embedded in the honeycomb core. They provide high thermal conductance through the thickness of the honeycomb and freeze nucleation sites. Two CCHPs (primary and redundant) transfer heat from the PCM to the LHP CC. Figure 3 shows the PCM heat exchanger concept. Basically some of the instrument electronics and/or detector assembly waste heat is stored in the PCM and transferred to the LHP CC by the CCHPs. Phase change of the PCM occurs at a constant temperature and maintains the LHP CC temperature stable.

After all the PCM is melted, continual heat transfer from the LHP evaporator to the PCM will increase the PCM temperature due to sensible heating. When the PCM temperature starts to increase, the VCHP reservoir heater will be switched on. The VCHP reservoir thermistor is located at the PCM. If the thermistor feedback to the controller is larger than the VCHP heater controller set point, the reservoir heater is powered on and the non-condensable gas expands. This stops heat transfer from the LHP evaporator to the PCM. Conversely, if the thermistor feedback to the controller is smaller than the VCHP heater controller set point, the reservoir heater is powered off and the noncondensable gas contracts. This allows heat transfer from the LHP evaporator to the PCM. The PCM melting point is conveniently selected as the heater controller set point. The tolerance of the heater controller can be as small as $\pm 0.1^{\circ} \mathrm{C}$. This innovative concept eliminates the need for heater power and precision heater controller for the LHP CC. It is a practical approach of waste heat utilization. It also increases the reliability of LHP.

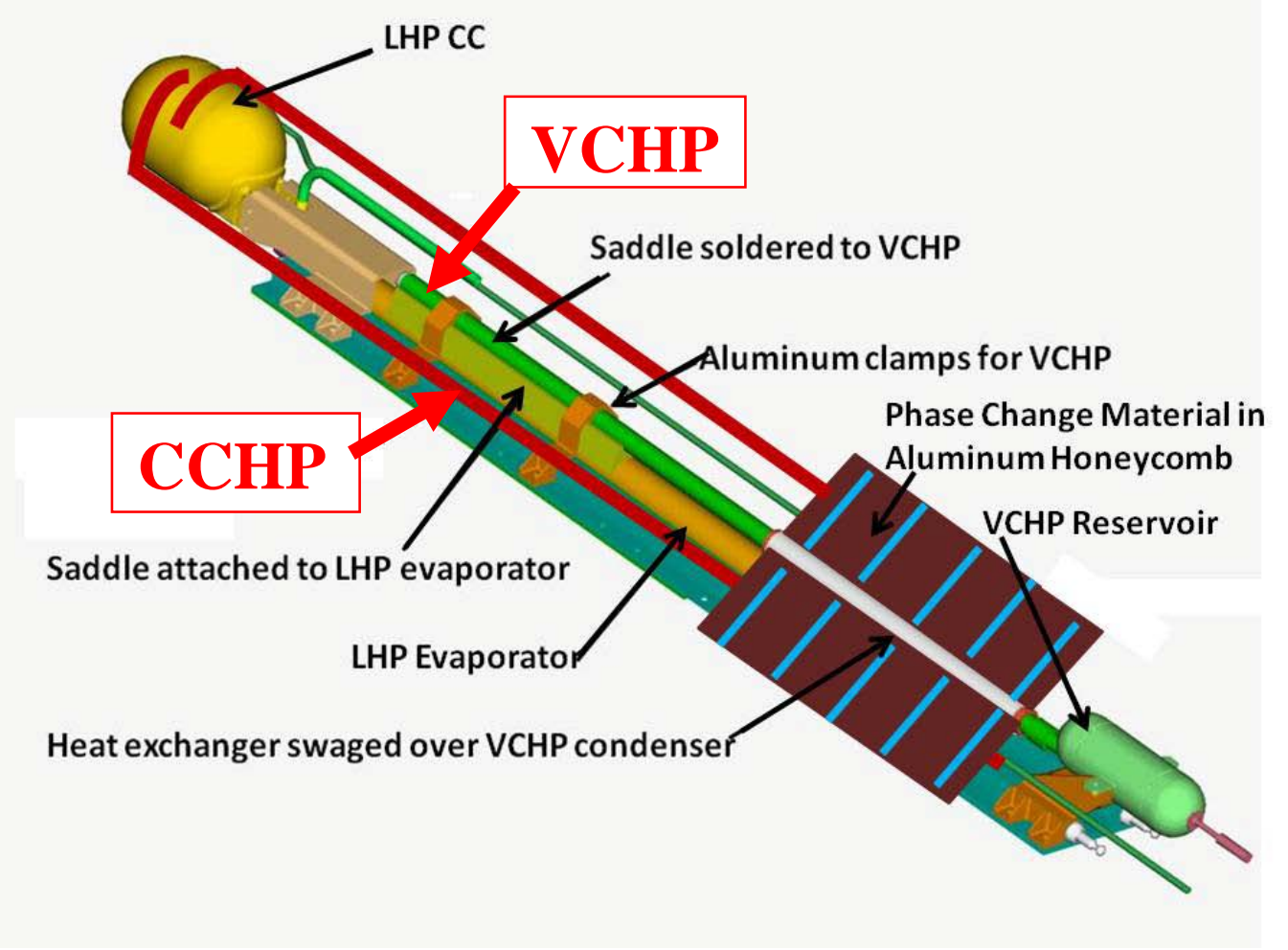

Figure 1. Concept of Using PCM for Temperature Control of LHP CC. 


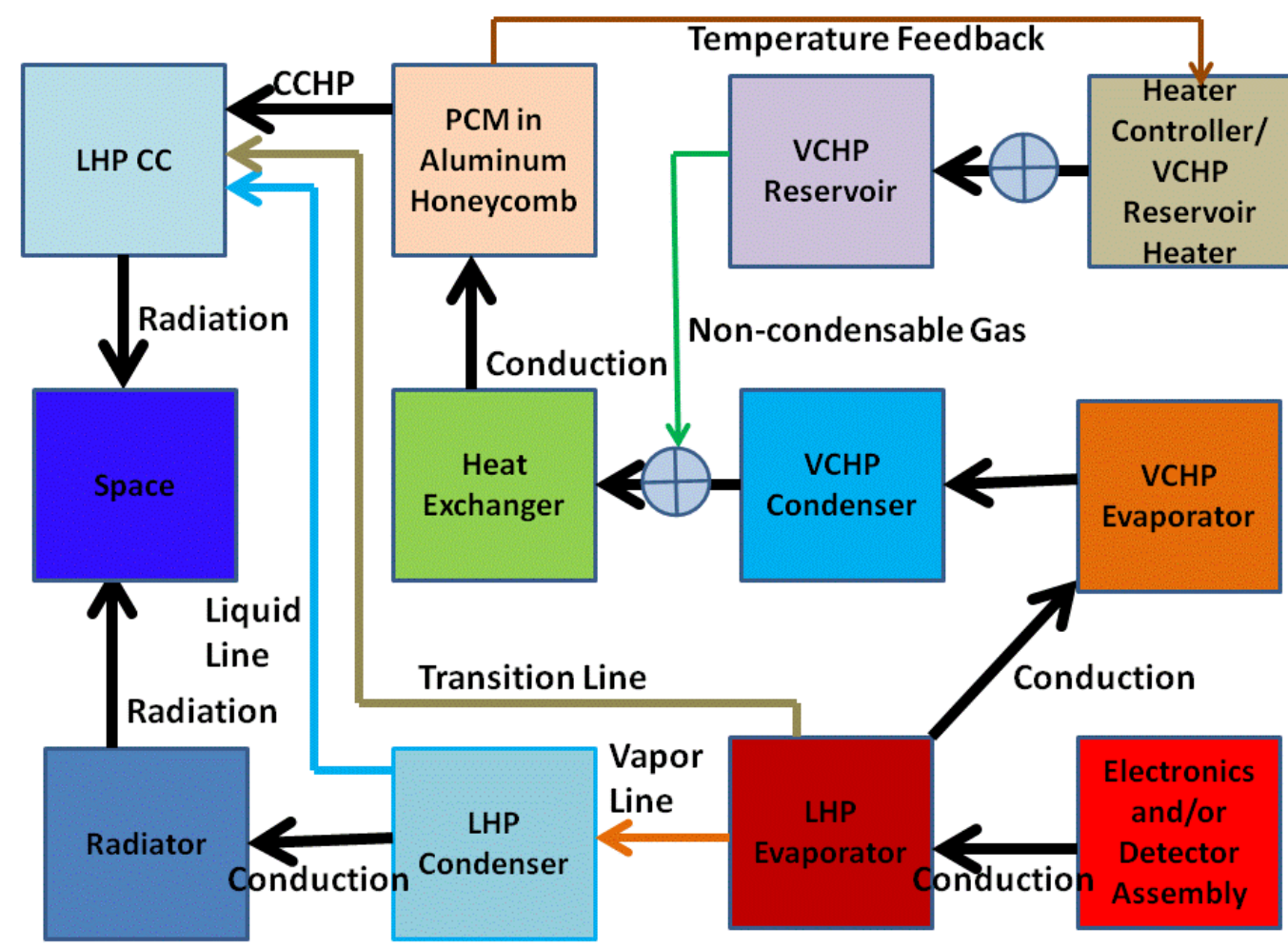

Figure 2. Functional Block Diagram for Innovative Concept.

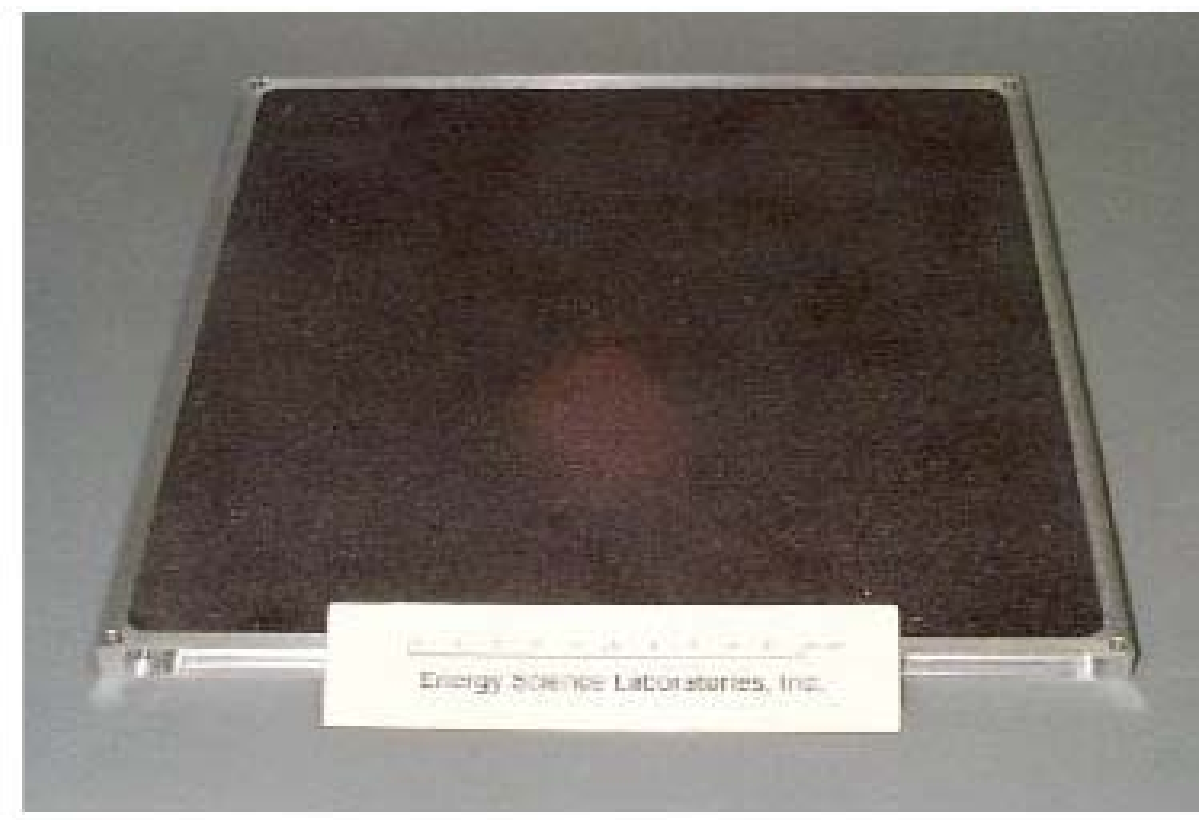

Figure 2. PCM Honeycomb Panel ${ }^{5}$ Concept.

Paraffin wax is a good PCM candidate. It has a high latent heat of fusion per unit mass, which is in the 155 to $253 \mathrm{~kJ} / \mathrm{kg}$ range (Fig. 3) ${ }^{5-9}$. It also has a range of melting points (Fig. 4) ${ }^{5-9}$. For example, $\mathrm{C}_{14} \mathrm{H}_{30}$ has a $5.5^{\circ} \mathrm{C}$ melting point which is close to the Swift BAT LHP CC temperature set point in flight. The technology readiness level (TRL) of paraffin PCM for space flight is at least 6. 


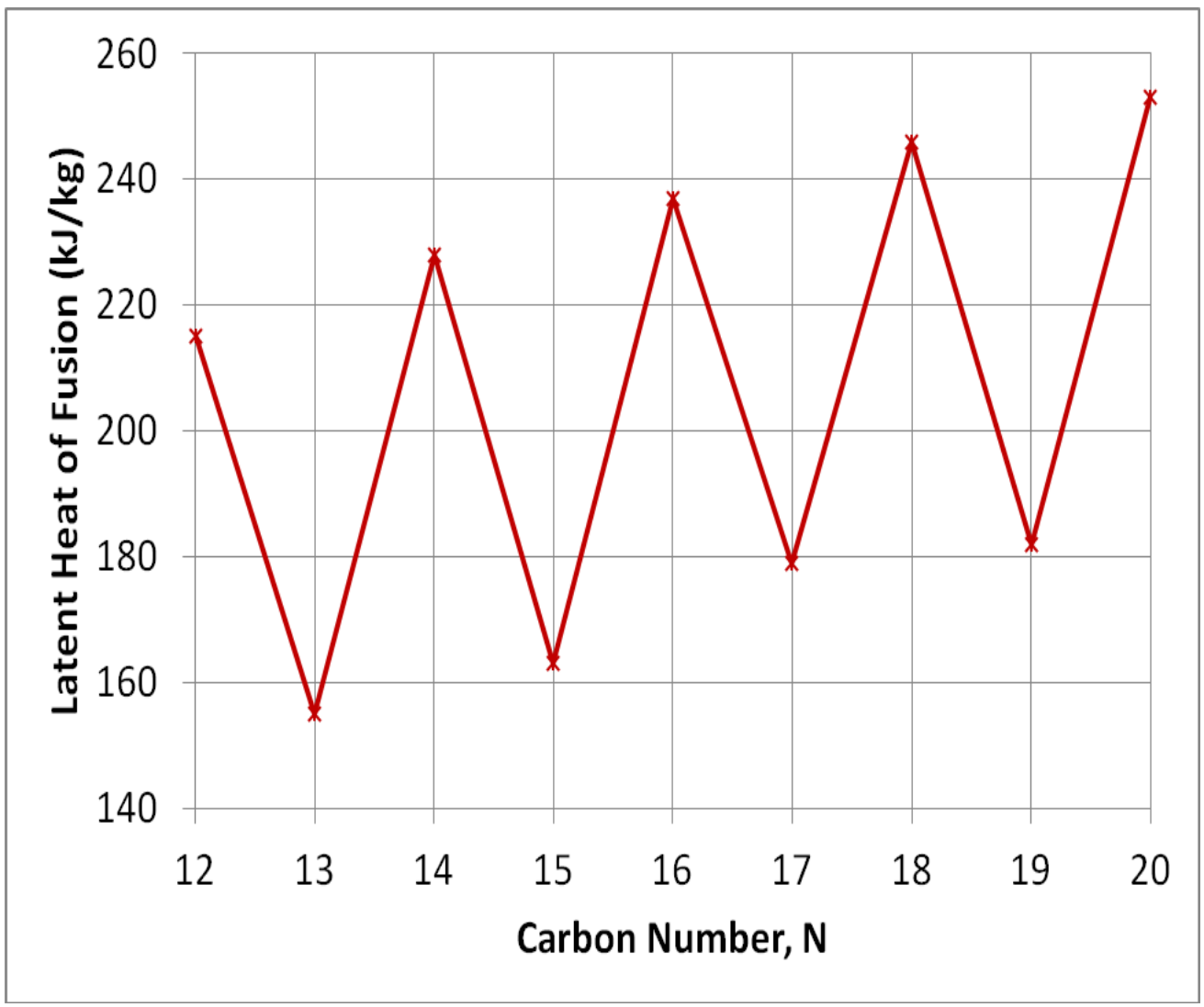

Figure 3. Latent Heat of Fusion of Paraffin $\left(\mathrm{C}_{\mathrm{N}} \mathrm{H}_{2 \mathrm{~N}+2}\right)$.

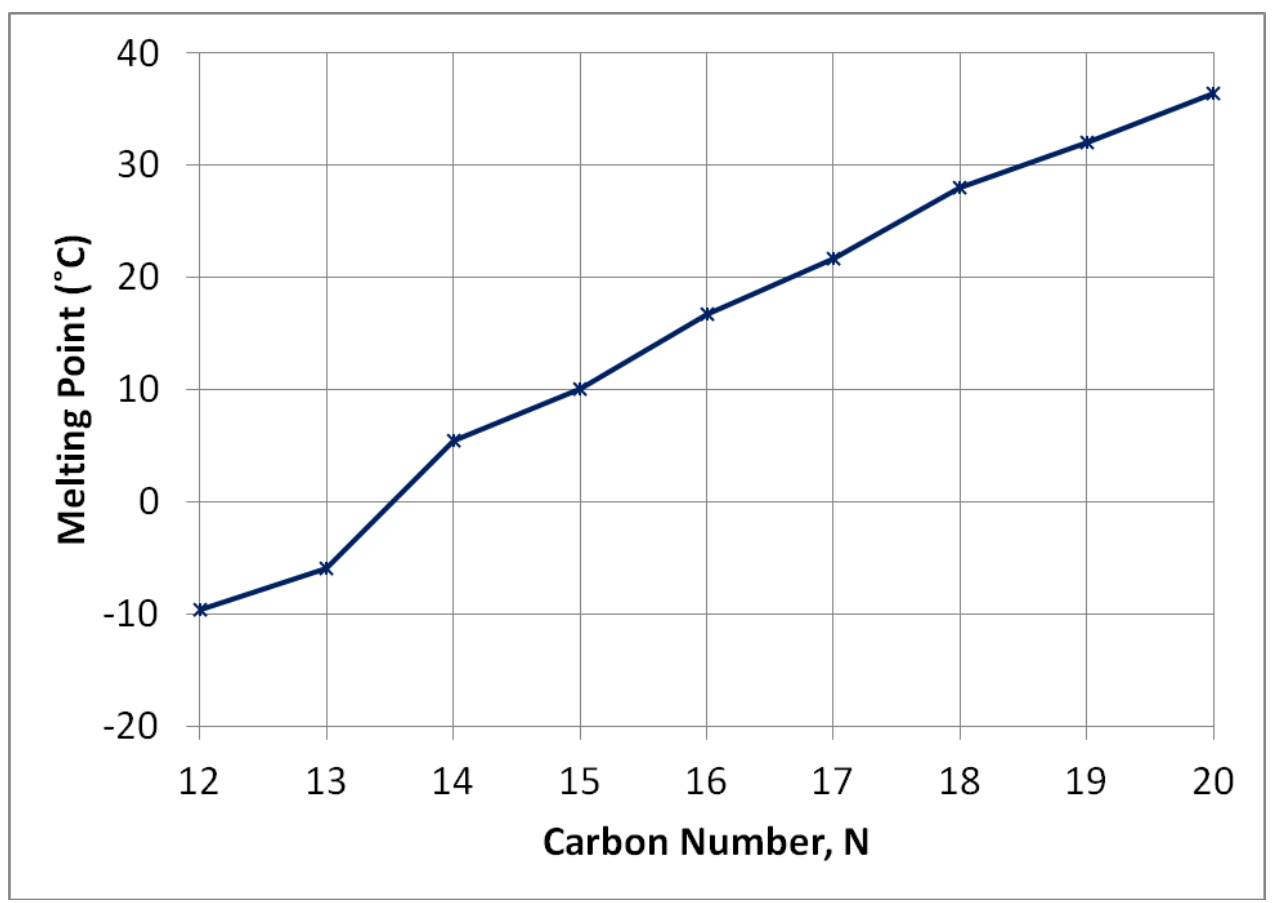

Figure 4. Melting Point of Paraffin $\left(\mathrm{C}_{\mathrm{N}} \mathrm{H}_{2 \mathrm{~N}+2}\right)$. 


\section{Case Study on PCM for Temperature Control of LHP CC}

As a case study in this paper, the PCM heat exchanger is analyzed for the propylene LHP flown on the Swift BAT instrument. Swift has an orbit of $600-\mathrm{km}$ altitude and $20.69^{\circ}$ inclination. Its orbit period is 96.7 minutes. The CC of each BAT LHP requires a $25 \mathrm{~W}$ heater power in the worst cold case. The following assumptions are made for the PCM heat exchanger:

- $0.64 \mathrm{~kg}$ of paraffin is used in the PCM heat exchanger.

- Aluminum honeycomb panel area is $20 \mathrm{~cm}$ x $20 \mathrm{~cm}$.

- Total thickness of paraffin PCM is $0.48 \mathrm{~cm}$.

- $50 \mathrm{~W}$ (24\% of detector module waste heat) is transferred to the PCM from the LHP evaporator for 96.7 minutes (one orbit); $158 \mathrm{~W}$ (76\% of detector module waste heat) is transported by LHP to radiator which radiates it to space.

- $25 \mathrm{~W}$ of heat is transferred from the PCM to the LHP CC by CCHPs.

This amount of paraffin can store $145 \mathrm{~kJ}$ of thermal energy as latent heat. It is adequate for the entire next orbit. Therefore the VCHP heater controller turns the reservoir heater on or off only once per orbit, and is about 5,000 times per year. For a 3-year mission, for example, it will be 15,000 times. Adding paraffin mass will increase the thermal energy stored by the PCM and reduce the number of times the controller turns the reservoir heater on/off. The VCHP reservoir heater power is a small fraction of that required for conventional active heater control of LHP CC. Therefore the overall heater power reduction is still large.

\section{Conclusion}

The innovative concept of using PCM for temperature control of LHP CC in this paper eliminates heater power and active heater control for the CC. It is a practical approach of waste heat utilization. It also increases the reliability of LHP. If multiple LHPs are used, the heater power savings is even larger. Although active heater control is required for the VCHP, the number of on/off cycles is typically about 5,000 per year. It should have a high reliability. The heater power required for the VCHP is much smaller than that required for the CC. If more paraffin is used, the number of heater controller on/off cycles decreases and the reliability is even better. Also the heater power required for the VCHP will be even smaller.

\section{References}

${ }^{1}$ Maydanik, Y., “Loop heat pipes”, Applied Thermal Engineering (2005), Volume: 25, Issue: 5-6, Pages: 635-657.

${ }^{2} \mathrm{Ku}$, J., “Operating Characteristics of Loop Heat Pipes”, SAE Transactions (1999) Volume: 108, Issue: 1, American Technical Publishers Ltd, Pages: 503-519.

${ }^{3} \mathrm{Ku}$, J., "Methods of Controlling the Loop Heat Pipe Operating Temperature", SAE International Conference on Environmental Systems, 30 June - 2 July, 2008, San Francisco, CA, Paper 2008-01-1998.

${ }^{4} \mathrm{Ku}$, J., et al., "Loop Heat Pipe Operation Using Heat Source Temperature for Set Point Control”, 2011 Spacecraft Thermal Control Workshop, El Segundo, CA, Mar. 8-10, 2011.

${ }^{5}$ Knowles, T. R., "Phase Change Composite Thermal Energy Storage”, Energy Science Laboratories, Inc., San Diego, CA, Sept. 2007.

${ }^{6}$ Hale, D. V., et al., Phase Change Materials Handbook, NASA-CR-61363, Sept. 1971.

${ }^{7}$ Poling, P. E., et al., Perry's Chemical Engineers' Handbook, $8^{\text {th }}$ ed., 2008, McGraw-Hill, New York.

${ }^{8}$ Knowles, T. R., "PCM Thermal Control of Nickel-Hydrogen Batteries”, PL-TR--93-1075, Phillips Laboratory, Kirtland Air Force Base, NM, June 1993.

${ }^{9}$ Kedl, R. J., “Wallboard with Latent Heat Storage for Passive Solar Applications”, ORNLTM-11541, Oak Ridge National Laboratory, Oak Ridge, TN, May 1991. 